\title{
Obituary: Hal Dixon
}

\section{Hans Vliegenthart}

(C) Springer Science + Business Media, LLC 2008

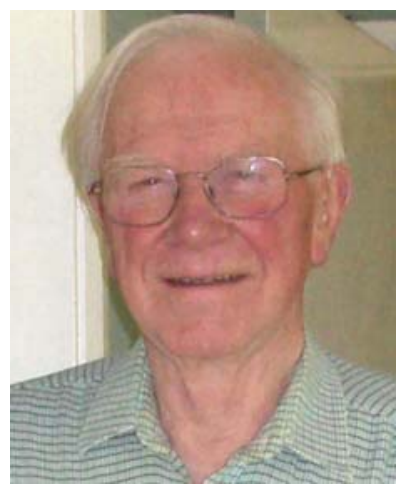

Dr. Hal (Henry Berkeley Franks) Dixon was born in Dublin, Ireland on May 16, 1928 and passed away in Cambridge, UK on July 30 . Already as a schoolboy he had a great interest in natural sciences. In 1946 Hal started his highly successful studies in biochemistry at Cambridge, U.K., Kings College. Subsequently, he did his $\mathrm{PhD}$ on studies of peptide hormones with Frank Young. In 1953 he became a Life Fellow of King's College. The PhD work was inspiring for him and during his whole career he kept a strong interest in peptide and protein (bio)chemistry. More than many other biochemists he had an open eye for the chemical aspects of these biomolecules. Therefore, he can be characterized as an outstanding chemical biochemist. His interest in and broad knowledge of the fundamental principles of organic chemistry and reaction mechanisms was of great importance for his formidable contributions to the enzyme nomenclature. The enzyme list is prepared and

H. Vliegenthart $(\bowtie)$

Bijvoet Center, Utrecht University,

Utrecht, The Netherlands

e-mail: j.f.g.vliegenthart@uu.nl kept up-to-date by the Nomenclature Committee of the International Union of Biochemistry and Molecular Biology (NC-IUBMB), in consultation with the IUPAC-IUBMB Joint Commission on Biochemical Nomenclature (JCBN). This list contains the nomenclature and classification of enzymes by the reaction they catalyze. An essential task of the committees is the development of a generally accepted coding system for all well characterized enzymes. This is not easy, since different names may be in use for one and the same enzyme. A further complication can be that scientists may prefer another type of classification or a subdivision according to fine specificities. Hal Dixon did a superb job by acting first as secretary, then as chairman of the nomenclature committees and later as advisory member. In these functions he was able to reach consensus on difficult nomenclature problems, thanks to his efficiency, dedication, irresistible enthusiasm, encyclopedic knowledge of (bio)chemical reactions, and open mind for deviating opinions. For the glycosciences and thereby for our journal, he gave valuable contributions to the carbohydrate, glycoprotein and glycolipid nomenclature documents. Such documents are relevant for carbohydrate and glycoconjugate (bio)chemistry. Serving such different scientific communities as synthetic chemists and biochemists is complicated. The nomenclature needs to be universal, accurate and unambiguous as well as not too complex to handle in daily practice. Hal Dixon was able to communicate with both. Hal Dixon loved his work as teacher and acted as a director of studies since 1961 for more than 20 years. He paid much attention to personal contacts with his students. For educational purposes he developed laboratory experiments to illustrate the theoretical principles. Hal Dixon was a real gentleman under all circumstances. He will be greatly missed by his family, and by his friends, colleagues and students. 